\title{
AN ASSOCIATION BETWEEN DIMENSIONS AND BRIDGING OF THE SELLA TURCICA AND DENTAL ANOMALIES
}

\author{
Seden Akan ${ }^{1 a}$, Nevin Kaptan Akar ${ }^{2 b}(\mathbb{1 0}$ \\ 'Department of Orthodontics, Faculty of Dentistry, Altınbaș University, Bakırköy / İstanbul, Turkey \\ 2Department of Orthodontics, İstanbul Medipol University Faculty of Dentistry, İstanbul, Turkey \\ aDDS, PhD, Assistant Professor; e-mail: sedenakandt@hotmail.com; 0RCIDiD: https://orcid.org/0000-0001-7955-3086 \\ bDS, PhD, Assistant Professor; e-mail: nakar@medipol.edu.tr; ORCIDiD: https://orcid.org/0000-0003-1208-6369
}

\begin{abstract}
do) https://doi.org/10.25241/stomaeduj.2021.8(1).art. 3

Introduction The aim of this study was to determine the incidence of bridging of the sella turcica and the dimensions of the Sella in subjects with dental anomalies (transpositions, hypodontia, and supernumerary teeth) and to compare them to controls.

Methodology Lateral cephalograms from 25 patients with dental transposition, 88 with hypodontia, and 26 with supernumerary teeth were evaluated. The shape, length, depth, diameter, and bridging of the Sella turcica were determined from radiographs and compared to those of control group $(n=52)$. For statistical analysis, one-way ANOVA, Tukey post-hoc test, chi-squared test and T-test (to evaluate the influence of craniofacial growth) were used.

Results The frequency of complete calcification of the Sella was greater in the group with supernumerary teeth (23\%) and in the group with hypodontia (14.7\%), while partial calcification of the Sella was more frequent in the control group $(77 \%)$ and in the group with supernumerary teeth $(73 \%)(p<0.05)$. The depth of the Sella was greater in the group with dental transposition. Oval and round Sella shapes were more frequent in all groups, and a flat Sella was rarely seen. In terms of the influence of growth on the dimensions of the Sella, there was no statistically significant difference between pre- and post-treatment radiographs. Conclusion Significant relationships were found between dental anomalies and bridging and shape of the Sella. The Sella was also significantly deeper in patients with dental transposition. The bridging and shape of the Sella may be useful in the diagnosis of dental anomalies in early childhood.
\end{abstract}

\section{KEYWORDS}

Sella Turcica Bridging; Hypodontia; Transposition; Supernumerary Tooth; Digital Radiography.

\section{INTRODUCTION}

The sella turcica is a depression in the middle line of the upper surface of the sphenoid bone. For orthodontists, the sella is a well-known anatomical structure on the scalp, because it is the central reference landmark in the evaluation of craniofacial morphology and the maxillomandibular relationship. The name sella turcica, Latin for "Turkish saddle," derives from the structure's similarity in shape to a saddle used by the Turks [1]. The anterior border of the sella turcica is marked by the tuberculum sella and the posterior border is marked by the dorsum sella [2]. The pituitary gland is located in the sella turcica, and two anterior and posterior clinoid processes project over the pituitary fossa [2].

During the embryological period, the sella turcica

(c) (1) (2) OPEN ACCESS This is an Open Access article under the CC BY-NC 4.0 license.

Peer-Reviewed Article

Citation: Akan S, Akar NK. An association between dimensions and bridging of the sella turcica and dental anomalies. Stoma Edu J. 2021;8(1):26-32.

Received: October 13, 2020; Revised: October 26, 2020; Accepted: November 13, 2020; Published: November 16, 2020

*Corresponding author: Dr. Seden Akan; Altınbaş Üniversitesi Diş Hekimliği Fakültesi Zuhuratbaba Mahallesi, İncirli Caddesi, No:11-A

34147 Bakırköy / İstanbul / Turkey.

Tel/Fax: 00905355113760 ; e-mail: sedenakandt@hotmail.com

Copyright: $\odot 2020$ the Editorial Council for the Stomatology Edu Journal. 

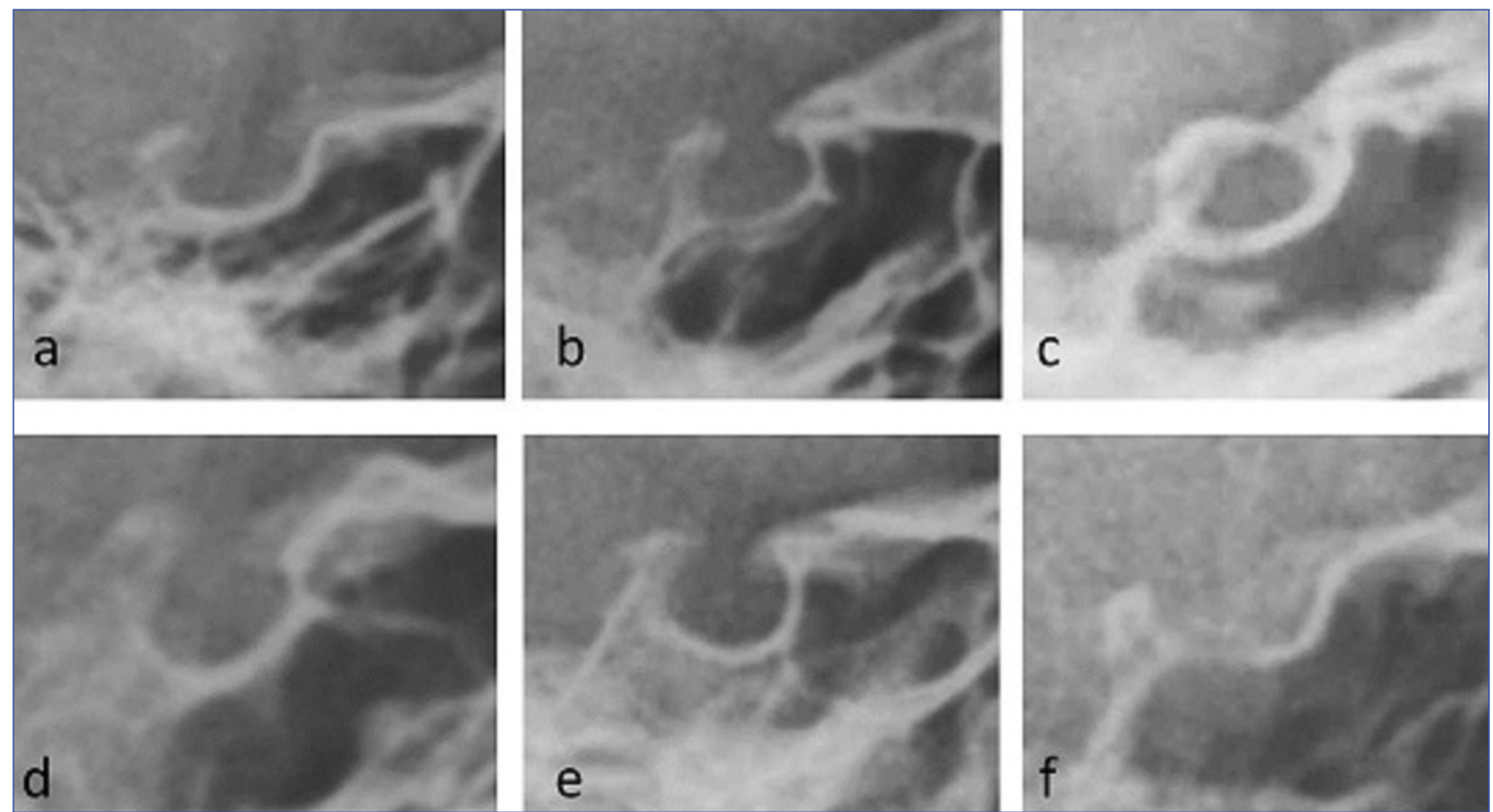

Figure 1. Classification of the bridging and shapes of the sella turcica: a) no calcification, b) partially calcified, and c) completely calcified; d) oval, e) round, andf) flat.

ITable 1. Descriptive statistics and gender distribution of study groups.

\begin{tabular}{|c|c|c|c|c|c|}
\hline & \multicolumn{5}{|c|}{ Group } \\
\hline & Transposition & Hypodontia & Supernumerary & Control & Total \\
\hline $\begin{array}{c}\text { Gender } \\
\text { Female/Male }\end{array}$ & $21 / 4$ & $55 / 33$ & $13 / 13$ & $33 / 19$ & $122 / 69$ \\
\hline Age (Mean \pm SD) & $15.81 \pm 3.51$ & $16.54 \pm 4.60$ & $16.60 \pm 4.30$ & $17.96 \pm 4.05$ & $16.84 \pm 4.31$ \\
\hline
\end{tabular}

Pvalue for age was 0.143

is the key point for the migration of the neural crest cells to the frontonasal and maxillary developmental fields [3]. The neural crest cells are involved in the formation and development of the sella turcica and the teeth [4]. Given this relationship between the sella turcica and the teeth, it has been argued that anatomic deviations in the sella turcica may be related to dental alterations. Thus, the morphology of the sella has been studied in relation to skeletal malocclusions [5,6], Down syndrome [7], cleft subjects [8], and dental anomalies such as dental transposition [9], absence of the second premolar [10], and palatally displaced canines [10].

In lateral cephalometry, the sella turcica is U-shaped. The size of the sella turcica has been evaluated widely in the literature and ranges from 4 to $12 \mathrm{~mm}$ in depth and from 5 to $16 \mathrm{~mm}$ for the anteroposterior diameter [11]. Three different shapes of the sella have been identified in the literature: oval, round, and flat. Of the three, the oval and round types are more common. The sella turcica is divided into three segments: an anterior wall, a floor, and a posterior wall [4]. Bridging of the sella turcica has been described as a bony union of the anterior and posterior clinoid processes. Bridging is regarded as an anatomical abnormality, and it is particularly prevalent in craniofacial deviations and developmental conditions such as basal cell carcinoma, Williams syndrome, Rieger syndrome, and other disorders [6]. The current study was therefore performed to evaluate the dimensions of the sella turcica and the incidence of bridging of the sella turcica in patients with dental anomalies (transpositions, hypodontia, and supernumerary teeth), to compare them with the controls, and to assess whether any significant changes occurred in the dimensions of the sella during craniofacial growth in patients with dental anomalies.

\section{MATERIALS AND METHODS}

\subsection{Study Population}

This retrospective radiographic study, approved by the institutional ethical board (ref. 10840098-604), was carried out on the cephalometric radiographs of 25 patients ( 21 females and four males) with dental transposition, 88 patients ( 55 females and 33 males) with hypodontia, and 26 patients ( 13 females and 13 males) with supernumerary teeth. Only patients with good-quality lateral cephalometric and panoramic radiographs were included in the study. The exclusion criteria were as follows: presence of any syndrome or systemic disease, previous orthodontic treatment, excess craniofacial deviations, and history of trauma. 


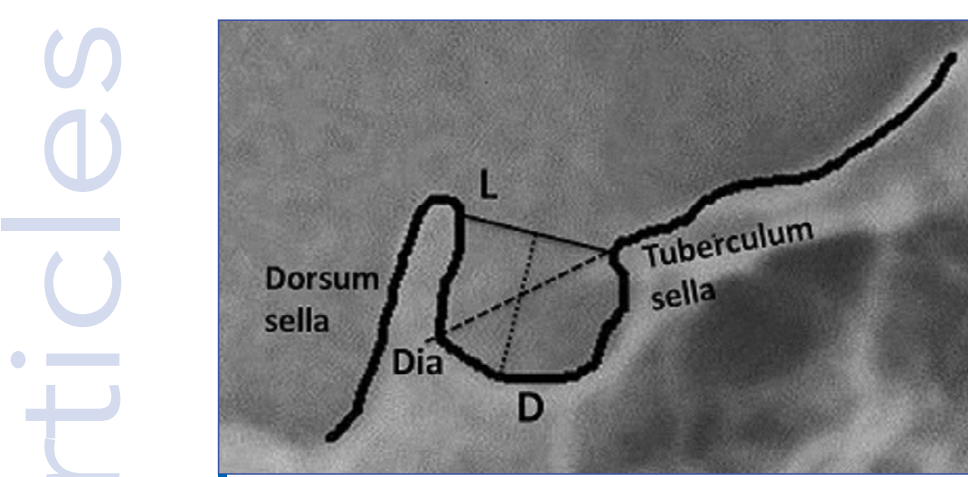

Figure 1. Reference lines and measurements of the sella turcica: $L=$ length of the sella, $D=$ depth of the sella, and Dia = greatest diameter of the sella.

The control group was created according to power analysis ( $a=0.05, f=0.25$, power $=0.80$ ) and consisted of 52 subjects ( 33 females and 19 males). The same inclusion and exclusion criteria were used as for the dental anomaly groups. The study groups are described in Table I.

\subsection{Cephalometric Analysis}

Pre-treatment lateral cephalometric and panoramic radiographs of all the patient groups and the control group were taken according to the standard technique for evaluating cranial structures, using a Kodak Extraoral Imaging System machine (Kodak 9000, Carestream Health, Inc., Rochester, NY, USA) and a cephalostat with a fixed magnification factor. Only radiographs with good-quality images of the Sella turcica area were selected for analysis. The region around the contour of the pituitary fossa from the tip of the dorsum sellae to the tuberculum sellae was traced on the lateral cephalometric images using acetate paper and a $0.5 \mathrm{~mm}$ lead pencil. The tracing and measurements were performed manually by one observer (SA) under ideal lighting conditions.

Bridging of the sella turcica was evaluated in accordance with the standardized scoring scale method of Leonardi et al. [10] A sella was scored as having "no calcification" when its length was greater than or equal to three-fourths of its diameter, as "partially calcified" when its length was less than three-fourths of its diameter, and as "completely calcified" when only the diaphragma sellae could be seen radiographically (Fig. 1). The linear characteristics of the sella turcica were measured in accordance with Silverman's method [12]. The length of the sella turcica was measured from the tuberculum sellae to the tip of the dorsum sellae. Its depth was measured perpendicularly to this line passing through the deepest point of the pituitary fossa. Its diameter was measured in the sagittal direction by drawing a line from the tuberculum sellae to the most distant point on the posterior inner wall of the fossa (Fig. 2). Morphologically, each sella turcica was classified as one of the three basic types (round, oval, or flat), in accordance with the

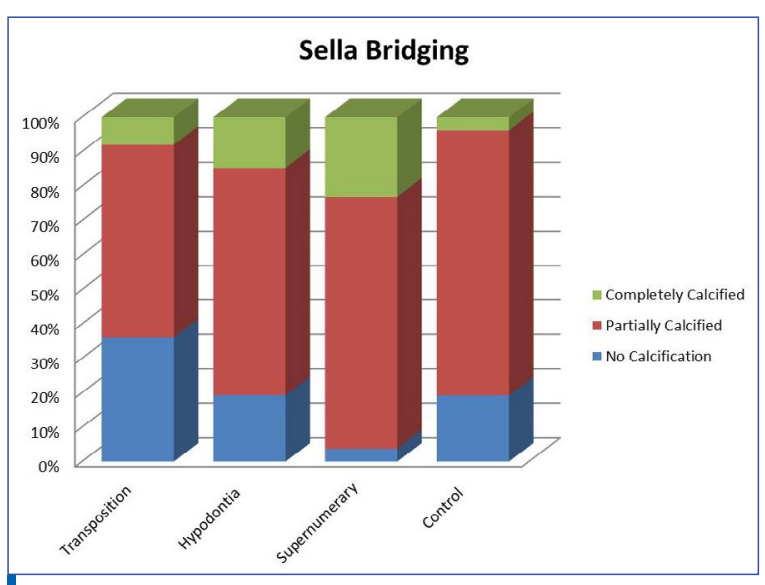

Figure 3. Sella bridging.

method of Jones et al. (Fig. 1) [13] .

\subsection{Evaluation of Influence of Craniofacial Growth}

To assess the possible effects of craniofacial growth on the size, shape, and bridging of the sella, posttreatment cephalometric radiographs of 15 patients selected at random from the study groups were compared to their pre-treatment radiographs. The mean time period between pre- and post-treatment radiographs was $3.21 \pm 1.19$ years.

\subsection{Statistical Analysis}

Analysis of the data was performed in the SPSS 16 package (SPSS for Windows, SPSS Inc., Chicago, IL, USA). Means, standard deviations, and minimum and maximum values were calculated, and the ShapiroWilks normality test was applied to the data. Oneway analysis of variance (ANOVA) and a Tukey post hoc test were used to assess differences between the linear dimensions of the groups, while nominal data were tested using a chi-squared test. A T-test was used to evaluate the influence of craniofacial growth on the measurements. To determine intra-rater reliability, 20 cephalometric radiographs selected at random were retraced after two weeks, and Pearson correlation coefficients were calculated (ranging from 0.810 to 0.862 ). The statistical significance was set at $p<0.05$.

\section{RESULTS}

Table I shows the descriptive statistics and $p$-values for the study groups and the control group. Table II shows the distribution of the degree of calcification of the sella turcica in the study and control groups. Complete calcification of the Sellawas more frequent in the group with supernumerary teeth $(23 \%)$ and in the group with hypodontia (14.7\%), while the partial calcification of the Sella was more frequent in the control group (77\%) and in the group with supernumerary teeth $(73 \%)(p=0.025)$.

The average linear dimensions of the sella turcica in the study groups and the control group are shown in Table II. The depth of the sella was greatest in the 
ITable 2. Distributions of the bridging types and the shapes of the sella, and average linear dimensions of the sella turcica in the study groups.

\begin{tabular}{|c|c|c|c|c|c|c|}
\hline & & \multicolumn{4}{|c|}{ Group } & \multirow[b]{2}{*}{$\mathbf{P}$} \\
\hline & & Trasposition & Hypodontia & Supernumerary & Control & \\
\hline \multirow{3}{*}{$\begin{array}{l}\text { Bridging Type } \\
\text { n(\%) } \\
\text { (x) }\end{array}$} & No Calcification & $9(36)$ & 17 (19.3) & $1(3.8)$ & $10(19.2)$ & \multirow{3}{*}{$0.025^{*}$} \\
\hline & $\begin{array}{l}\text { Partially } \\
\text { Calcified }\end{array}$ & $14(56)$ & $58(66)$ & $19(73.1)$ & $40(77)$ & \\
\hline & $\begin{array}{l}\text { Completelly } \\
\text { Calcified }\end{array}$ & $2(8)$ & $13(14.7)$ & $6(23.1)$ & $2(3.8)$ & \\
\hline \multirow{3}{*}{$\begin{array}{c}\text { Linear } \\
\text { Dimensions } \\
\text { (Mean } \pm \text { SD) } \\
\text { (à) }\end{array}$} & Length & $5.04 \pm 2.75$ & $4.48 \pm 2.78$ & $3.88 \pm 2.37$ & $4.71 \pm 2.34$ & 0.421 \\
\hline & Depth & $7.48 \pm 1.36$ & $6.93 \pm 1.26$ & $6.42 \pm 1.10$ & $6.86 \pm 0.99$ & $0.018^{*}$ \\
\hline & Diamater & $9.12 \pm 1.83$ & $8.40 \pm 2.13$ & $7.92 \pm 1.63$ & $8.33 \pm 1.63$ & 0.154 \\
\hline \multirow{3}{*}{$\begin{array}{c}\text { Shape of Sella } \\
\mathbf{n}(\%) \\
(\mathbf{x})\end{array}$} & Oval & $5(20)$ & $10(11.4)$ & $13(50)$ & 19 (36.5) & \multirow{3}{*}{$0.001^{* *}$} \\
\hline & Round & $18(72)$ & 69 (78.4) & $13(50)$ & $27(52)$ & \\
\hline & Flat & $2(8)$ & $9(10.2)$ & 0 & $6(11.3)$ & \\
\hline
\end{tabular}

(x) means Chi square statistics, ${ }^{*} \mathrm{P}<0.05$. (à) means ANOVA test ${ }^{*} \mathrm{P}<0.05$. According to Tukey Post hoc test; a statistically significant difference was found only between transposition and supernumerary groups $\mathrm{P}=0.009^{*}$

group with dental transposition, and the difference from the group with supernumerary teeth was statistically significant $(p<0.05)$. The distribution of the shape of the sella turcica in the study and control groups is also shown in Table II. Oval and round shapes were more frequent in all groups, and a flat sella was rarely seen $(p=0.001)$. According to the results of the T-test, there was no statistically significant difference between the pre- and posttreatment radiographs in terms of the influence of the growth on the dimensions and bridging of the sella.

\section{DISCUSSION}

In this retrospective study, certain characteristics and dimensions of the sella turcica were analyzed on pre-treatment standardized lateral cephalometric radiographs. The aim was to assess the shapes, dimensions, and the incidence of bridging of the sella turcica in subjects with dental anomalies (transpositions, hypodontia, and supernumerary teeth) compared to control subjects. These parameters have not previously been studied in Turkish orthodontic patients. The literature reports sella bridging, defined as ossification between the anterior and posterior clinoid processes in the dura mater, as a determinant factor for dental anomalies. Although bridging is seen in healthy subjects [14], it occurs more frequently in subjects with craniofacial deviations (i.e. carcinomas [15], syndromes [16], and skeletal malocclusions $[17,18]$ ). From an embryologic point of view, the anterior wall of the sella turcica develops from neural crest cells, as teeth do; thus, deviations in the anterior wall are believed to be related to dental anomalies [14]. In the present study, bridging of the sella turcica at the completely calcified level was seen in $23.1 \%$ of the patients with supernumerary teeth, in $14.7 \%$ of the patients with hypodontia, in $8 \%$ of the patients with transposition, and in $3.8 \%$ of the control patients (total frequency $=12 \%$ ). Bridging at the partially calcified level was seen in $73.1 \%$ of the patients with supernumerary teeth, in $66 \%$ of the patients with hypodontia, in $56 \%$ of the patients with transposition, and in $77 \%$ of the control patients (total frequency $=68.6 \%$ ). The findings of the present study are different from those of comparable studies. For example, in patients with supernumerary teeth, bridging of the sella turcica has previously been reported at the partially calcified level in 53\% of the patients and at completely calcified level in $6 \%$ of the patients; in that study, the levels for the control patients were $30 \%$ and $13 \%$, respectively [19]. In a study of patients with transposition, $42.9 \%$ were at the partially calcified level and $23.8 \%$ at the completely calcified level; the levels for the control patients were $68.6 \%$ and $5.7 \%$, respectively [9]. In a study of patients with supernumerary teeth, $21.7 \%$ were at the partially calcified level and $21.7 \%$ were at the completely calcified level; the levels for the control patients were $19.4 \%$ and $5.6 \%$, respectively [20]. These differences between previous studies and the present findings may be due to the number of patients included in each study and the nature of their existing malformations, as bridging of the sella turcica has been related in the literature to craniofacial deviations. Many studies have reported patients with Class III malocclusion as having a greater proportion of bridging of the sella than Class I patients $[17,18,21]$. The size of the sella turcica has 
been studied in detail in the literature, with the linear measurements ranging from 4 to $12 \mathrm{~mm}$ in depth and 5 to $16 \mathrm{~mm}$ in length $[11,12]$. In the present study, there were no statistically significant differences between the patient groups; lengths ranged from 3.88 to $5.04 \mathrm{~mm}$ and diameters from 7.92 to $9.12 \mathrm{~mm}$. There was a statistically significant difference in the depth of the sella between the patients with transposition $(7.48 \mathrm{~mm})$ and those with supernumerary teeth $(6.42 \mathrm{~mm})(p=0.018)$. The difference between the present findings and the measurements in the literature may be due to the use of different landmarks and levels of radiographic magnification. Some studies have revealed a correlation between the linear dimensions of the Sella and age and growth as factors associated with bridging of the sella [22], whereas others have denied any association [23]. In the present study, the effects of growth on the characteristics of the sella were evaluated by measuring the size, shape, and bridging of the sella on the pre- and postorthodontic cephalometric radiographs of 15 patients. No statistically significant difference $(p>0.05)$ was found in either the pre-treatment or the posttreatment data; however, the correlation between the sella characteristics and age should be analyzed on a larger sample of cephalograms. The shape of the sella turcica is affected by anatomical structures: the pituitary gland, the extent of the anterior and posterior intercavernous venous sinuses [24], and the internal carotid artery [25]. The shape of the sella turcica is also determined genetically [26]. In the present study, the shape of the Sella turcica was classified as oval, round, or flat, in line with the approach taken by Jones et al [13]. Although Jones et al. [20] did not provide any data about the prevalence of the different shapes, other studies have shown the oval shape to be the most common among Nigerian subjects [27]. In the present study, consistent with the literature, the round shape was the most common in all groups, followed by the oval shape and then the flat type. This study was limited by a number of factors, including a lack of gender discrimination between the groups. Some studies have suggested that there is no gender correlation in terms of the linear dimensions of the sella $[6,28,29]$. In the present study, gender data were taken into account, and thus the ratio of female to male patients in the study groups was balanced. A further limitation is that this study used two-dimensional lateral cephalometric radiographs instead of threedimensional cone beam computerized tomography images, which limited the capacity to determine the characteristics of the sella turcica. Three-dimensional images are more informative and reliable, but they are no routine diagnostic tools in orthodontics for the dental anomalies under study here.

The clinical relevance of the present study relates to early diagnosis of dental anomalies. The findings may allow clinicians to provide preventive measures for specific patient groups, especially with a diagnosis of transposition and the possibility of supernumerary teeth in the early period.

\section{CONCLUSION}

The findings of the present study indicate that bridging of the sella turcica was more frequent in patients with supernumerary teeth and hypodontia. The sella was deeper in patients with transposition, and in terms of shape, oval and round sellae were the most frequent in all groups. Although the study groups were not divided according to age, the results of the growth evaluation showed no significant change in the dimensions of the sella during craniofacial growth in patients with dental anomalies.

\section{CONFLICT OF INTEREST}

The authors declare no conflict of interest.

\section{ACKNOWLEDGMENTS}

None.

\section{AUTHOR CONTRIBUTIONS}

SA: contributed to the concept and design of the study, the acquisition, analysis and interpretation of the data and drafting the article. NKA: participated by adding her patient records and revising the article critically. All authors read and approved the final manuscript.

FUNDING

The authors declare that they have not received any funding.

\section{COMPETING INTERESTS}

The authors declare that they have no competing interests.

\section{ETHICS APPROVAL AND CONSENT TO PARTICIPATE}

A written informed consent containing all the information about records and usage for study was obtained from all patients. All procedures in this study were approved by the Ethical Board of the Istanbul Medipol University (10840098-604) and complied with the Code of Ethics of the World Medical Association (Declaration of Helsinki). 


\section{REFERENCES}

1. Nagaraj $T$, Shruthi $R$, James $L$, et al. The size and morphology of sella turcica: a lateral cephalometric study. J Med Radiol Pathol Surg. 2015;1(3):3-7.

GoogleScholar

2. Tassoker M, Ozcan S. Clinical and radiological significance of sella turcica: A Literature Review. IOSR Journal of Dental and Medical Sciences (IOSR-JDMS). 2016;15(2):108-113.

CrossRef Google Scholar

3. Ani S, James J, Prasanth SP. Morphology of Sella Turcica in Skeletal Class II Subjects. Journal of Research and Practice in Dentistry. 2015 Article ID 109848: doi: 10.5171/2015.109848. CrossRef GoogleScholar

4. Sathyanarayana HP, Kailasam V, Chitharanjan AB. Sella turcicaIts importance in orthodontics and craniofacial morphology. Dent Res J (Isfahan). 2013;10(5):571-575.

Full text links GoogleScholar

5. Sobuti F, Dadgar S,Seifi A, et al. Relationship between bridging and dimensions of sella turcica with classification of craniofacial skeleton. Pol J Radiol. 2018;83(3):e120-e126.

Full text links CrossRef GoogleScholar Scopus WoS

6. Meyer-Marcotty P, Reuther T, Stellzig-Eisenhauer A. Bridging of the sella turcica in skeletal Class III subjects. Eur J Orthod. 2010;32(2):148-153. https://doi.org/10.1093/ejo/cjp081 Full text links CrossRef GoogleScholar Scopus WoS 7. Korayem M, AlKofide E. Size and shape of the sella turcica in subjects with Down syndrome. Orthod Craniofac Res. 2015;18(1):43-50. https://doi.org/10.1111/ocr.12059 Full text links CrossRef GoogleScholar Scopus WoS 8. Cesur E, Altug AT, Toygar-Memikoglu U, et al. Assessment of sella turcica area and skeletal maturation patterns of children with unilateral cleft lip and palate. Orthod Craniofac Res. 2018;21(2):78-83. https://doi.org/10.1111/ocr.12219 Full text links CrossRef GoogleScholar Scopus WoS 9. Leonardi R, Farella M, Cobourne MT. An association between sella turcica bridging and dental transposition. Eur J Orthod. 2011;33(4):461-465. https://doi.org/10.1093/ejo/cjq106

Full text links CrossRef GoogleScholar Scopus WoS

10. Leonardi R, Barbato E, Vichi M, et al. A sella turcica bridge in subjects with dental anomalies. Eur J Orthod. 2006;28(6):580-585. https://doi.org/10.1093/ejo/cjl032

Full text links CrossRef GoogleScholar Scopus WoS

11. Choi WJ, Hwang EH, Lee SE. The study of shape and size of normal sella turcica in cephalometric radiographs. Korean J Oral Maxillofac Radiol. 2001;31(5):43-49.

GoogleScholar

12. Silverman FN. Roentgen standards for size of the pituitary fossa from infancy through adolescence. Am J Roentgenol Radium Ther Nucl Med. 1957;78(3):451-460.

PubMed GoogleScholar Scopus

13. Jones RM, Faqir A, Millet DT, et al. Bridging and dimensions of sella turcica in subjects treated by surgical orthodontics means or orthodontics only. Angle Orthod. 2004;75(5):714-718. https:// doi.org/10.1043/0003-3219(2005)75[714:BADOST]2.0.CO;2 PubMed GoogleScholar Scopus

14. Brahmbhatt RJ, Bansal M, Mehta C, et al. Prevalence and dimensions of complete sella turcica bridges and its clinical significance. Indian J Surg. 2015;77(2):299-301. https://doi. org/10.1007/s12262-012-0800-5

Full text links CrossRef GoogleScholar Scopus WoS 15. Kjaer I, Wagner A, Madsen P, et al. The sella turcica in children with lumbosacral myelomeningocele. Eur J Orthod. 1998;20(4):443-448. https://doi.org/10.1093/ejo/20.4.443 Full text links CrossRef GoogleScholar Scopus WoS
16. Koshino T, Konno T, Ohzeki T. Bone and joint manifestations of Rieger's syndrome: a report of a family. J Pediatr Orthop. 1989:9(2):224-230.

PubMed CrossRef GoogleScholar Scopus

17. Becktor JP, Einersen S, Kjaer I. A sella turcica bridge in subjects with severe craniofacial deviations. Eur J Orthod. 2000;22(1):69-74. https://doi.org/10.1093/ejo/22.1.69 Full text links CrossRef GoogleScholar Scopus WoS 18. Marsan G, Oztas E. Incidence of bridging and dimensions of sella turcica in class I and class III Turkish adult female patients. World J Orthod. 2009;10(2):99-103.

PubMed GoogleScholar Scopus

19. Scribante A, Sfondrini MF, Cassani M, et al. Sella turcica bridging and dental anomalies: is there an association? Int J Paediatr Dent. 2017;27(6):568-573. https://doi.org/10.1111/ipd.12301 Full text links CrossRef GoogleScholar

20. Divya S, Urala AS, Prasad GL, et al. Sella turcica bridging a diagnostic marker for impacted canines and supernumerary teeth. J Int Oral Health. 2018;10(2):94-98. https://doi.org/10.4103/ jioh.jioh 27617

CrossRef GoogleScholar Scopus

21. Abdel-Kader HM. Sella turcica bridges in orthodontic and orthognathic surgery patients. A retrospective cephalometric study. Aust Orthod J. 2007;23(1):30-35.

PubMed GoogleScholar Scopus

22. Prabhakar R, Rajakumar P, Karthikeyan MK, et al. A hard tissue cephalometric comparative study between hand tracing and computerized tracing. J Pharm Bioallied Sci. 2014;6(5): 101-106. https://doi.org/10.4103/0975-7406.137401

Full text links CrossRef GoogleScholar Scopus WoS

23. Elster AD, Chen MY, Williams DW, et al. Pituitary gland: MR imaging of physiologic hypertrophy in adolescence. Radiology. 1990;174(3 pt 1): 681-685. https://doi.org/10.1148/radiology.174.3.2305049

Full text links CrossRef Google Scholar

24. Renn WH, Rhoton AL Jr. Microsurgical anatomy of the sellar region. J Neurosurg. 1975;43(3):288-298. https://doi.org/10.3171/ jns.1975.43.3.0288

Full text links CrossRef GoogleScholar

25. Inoue T, Rhoton AL Jr, Theele D, et al. Surgical approaches to the cavernous sinus: a microsurgical study. Neurosurgery. 1990;26(6):903-932. https://doi.org/10.1097/00006123199006000-00001

Full text links CrossRef GoogleScholar

26. Brock-Jacobsen MT, Pallisgaard C, Kjaer I. The morphology of the sella turcica in monozygotic twins. Twin Res Hum Genet. 2009;12(6):598-604. https://doi.org/10.1375/twin.12.6.598 Full text links CrossRef GoogleScholar 27. Zagga AD, Ahmed H, Tadros AA, et al. Description of the normal variants of the anatomical shapes of the sella turcica using plain radiographs: experience from Sokoto, Northwestern Nigeria. Ann Afr Med. 2008;7:77-81.

Full text links CrossRef GoogleScholar

28. Alkofide EA. The shape and size of the sella turcica in skeetal Class I, Class II, and Class III Saudi subjects. Eur J Orthod. 2007;29(5): 457-463. https://doi.org/10.1093/ejo/cjm049 Full text links CrossRef GoogleScholar

29. Axelsson S, Storhaug K, Kjær I. Post-natal size and morphology of the sella turcica. Longitudinal cephalometric standards for Norwegians between 6 and 21 years of age. Eur J Orthod. 2004;26(6): 597-600. https://doi.org/10.1093/ejo/26.6.597. Full text links CrossRef GoogleScholar 


\section{Seden AKAN \\ Department of Orthodontics \\ Faculty of Dentistry \\ Altınbaș University \\ Bakırköy / İstanbul, Turkey}

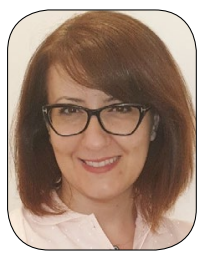

Seden Akan graduated from the Hacettepe University, Faculty of Dentistry, Ankara, Turkey in 2003. She enrolled for her PhD degree in 2004 and she was awarded her PhD degree by the Hacettepe University in 2010.

Since 2018, she has been working as an Assistant Professor at the Department of Orthodontics within the Faculty of Dentistry of the Altınbaș University, Bakırköy / İstanbul, Turkey.

\section{Ouestions}

\section{What is the key point for seeking a relationship between the Sella turcica and dental malocclusions?}

Da. The anterior wall of the Sella turcica and teeth share in common the involvement of neural crest cells;

ab. Their close neighborhood;

ac. The effect of pituitary gland secretion;

d. The shape of the sphenoid bone.

\section{In the present study, the shapes of the Sella turcica identified in:}

Da. Round;

ab. Oval;

ac. Flat:

$\square d$. Answers a-d are correct.

\section{Sella turcica bridging is especially seen in the following cases:}

Da. Craniofacial deviations;

ab. Developmental conditions;

uc. Skeletal malocclusions;

ud. Answers a-d are correct.

\section{According to the present study results, the complete calcification of the Sella was} shown in the...

Da. Transposition group;

ab. Hypodontia group;

ac. Supernumerary teeth group;

ud. Impacted teeth group. 